\title{
THE CRYSTALLINE STRUCTURE OF ICE
}

\author{
By P. G. Owston and Kathleen Lonsdale, F.R.S. (University College, London)
}

\begin{abstract}
Only one form of natural ice has been proved to exist at ordinary pressures. The positions of the oxygen atoms are known definitely from X-ray investigation. These form an open-work structure in which each oxygen is surrounded tetrahedrally by four others, the whole system having hexagonal symmetry. The positions of the hydrogen atoms between each pair of oxygens are not known with certainty, perhaps because they may be continually changing. Curious diffuse X-ray patterns, which are related to the temperature of ice, have yet to be explained in detail, but may throw light on the atomic movements. A cubic form of ice may exist at temperatures below $-70^{\circ} \mathrm{C}$. and under special conditions, and some less symmetrical high pressure forms have also been studied.
\end{abstract}

Zusammenfassung. Bei gewöhnlichem Druck wurde bisher nur eine Form von natürlichem Eis nachgewiesen. Die Stellung der Sauerstoffatome ist durch Röntgenanalyse mit Sicherheit bestimmt. Diese bilden eine mit Lücken durchsetzte Struktur, in der jedes Sauerstoffatom tetraederförmig von vier anderen umgeben ist, und zwar so, dass die Struktur als Garizes hexagonale Symmetrie besitzt. Die Stellungen der zwischen je einem Paar von benachbarten Sauerstoffatomem eingefügten Wasserstoffatome sind nich mit Sicherheit bekannt, was darauf zurückzuführen sein mag, dass sie ihre Stellungen ständig wechseln. Merkwürdige diffuse Röntgenbeugungserscheinungen, die mit der Temperatur des Eises in Zusammenhang stehen, werden vielleicht $\mathrm{zu}$ einem Verständnis dieser Atombewegungen führen, sind aber bisher nicht in ihren Einzelheiten erklärt worden. Bei Temperaturen unter $-70^{\circ}$ und unter speziellen Bedingungen dürfte auch eine kubische Form des Eises beständig sein. Verschiedene Hochdruckformen niedrigerer Symmetrie wurden ebenfalls untersucht.

Almost all ice is crystalline, and much natural ice is monocrystalline, yet single crystals of ice are seldom well enough developed to be useful to the crystallographer, except in a rather elementary way. Ice obviously has at least trigonal symmetry; but it has been variously described as ditrigonal pyramidal, ditrigonal scalenohedral, ditrigonal bipyramidal, hexagonal bipyramidal, dihexagonal pyramidal, dihexagonal bipyramidal and rhombohedral. Sheet ice, formed on the surface of slowly freezing water, usually grows in large (often very large) single crystals with the basal plane (oo.I) as the exposed surface. But it grows no other natural faces unless it develops as needles or laths, in which case it may have the [OO.I] or the [1 1.0$]$ axis along the length of the crystals, which do not, however, then show properly developed end-faces. Snowflakes, though supremely beautiful, are too complex in habit to reveal the true symmetry of the underlying structure, while hailstones, though monocrystalline or composed at most of a few individual crystals, ${ }^{1}$ usually show no external form. In 1930 Adams $^{2}$ concluded that ice must belong to a hexagonal polar class, since he observed asymmetrical etch-pits. It is possible, however, that the presence of impurities may have affected the very small artificial crystals he used, since neither piezo- nor pyro-electrical effects have been observed in ice. ${ }^{3} \mathrm{On}$ the other hand, such polar properties might be masked by twinning; Adams quotes observations of asymmetric hailstones by Smithson in 1823 and of asymmetric snowflakes by Dobrowolski in 1916, in support of his own study of polar artificially frozen ice crystals.

To a certain extent, however, this discussion of the symmetry of ice is academic, for there is no doubt about the positions of the oxygen atoms, and these decide many of the properties of ice. $\mathrm{X}$-ray methods of structure analysis ${ }^{4}$ have shown that the oxygen atoms are arranged as shown in Fig. 2 (p. 123). Each oxygen atom in this structure has four other oxygen atoms equidistant from it, $2 \cdot 76$ A.U. away, at the corners of a regular tetrahedron of which it is the centre. There are four oxygen atoms in each unit of the regularly repeated pattern, the cell dimensions being given 
by Megaw ${ }^{5}$ as $a=4.5226$ A.U., $c=7 \cdot 3670$ A.U. at $0^{\circ}$ C.; $a=4.5176$ A.U., $c=7 \cdot 353$ A.U. at $-66^{\circ}$ C. (all corrected to true c.g.s. units. Megaw's original values were in wave-length units). These give a mean coefficient of linear expansion over the temperature range $-66^{\circ}$ to $0^{\circ} \mathrm{C}$. of 29 ( \pm 10$) \cdot 10^{-6}$ along the hexagonal axis $c$, and of 17 ( \pm 10$) \cdot 10^{-6}$ along the perpendicular $a$ direction. This difference in the linear expansion coefficient * is the result of a difference in the strength of binding together of the atoms along, and at right angles to, the principal axis. This difference is shown very strikingly, of course, by the relative ease with which ice will cleave or slip parallel to the basal plane ${ }^{6}$ Careful examination of a three-dimensional model of the structure shows that the cleavage parallel to (oo.r) involves the rupture of only two bonds per unit cell, these being normal to the cleavage plane, whereas cleavage along any plane at right angles to (O०.I) requires the rupture of at least four bonds per unit cell, these four being inclined to the plane, so that the atoms they link together are closer in projection than the atoms which are separated by the principal cleavage (see Fig. 3, p. 123).

Now what is the nature of the bonds between the oxygen atoms? That is a question which is much more difficult to answer; indeed, it has not yet been fully answered. There are two hydrogen atoms to each oxygen in the structure, but their scattering power for X-rays is so small that so far, at least, X-ray analysis has failed to locate them. Neutron scattering might be more successful, but even this is doubtful because it may be that they have no fixed location; certainly that possibility has to be explored. Barnes, in his structure analysis, assumed that ice is ionic, with hydrogen nuclei midway between pairs of oxygen ions; but this is very unlikely. It would involve an oxygen to hydrogen distance of $\mathrm{r} \cdot 38$ A.U., and a big change in the infra-red and Raman spectra on passing from water-vapour or water (which are certainly molecular) to ice. Such a change does not occur. The latest analysis of the vibration-rotation spectrum of water-vapour ${ }^{7}$ shows that the hydrogen nuclei are $0.95^{8} \mathrm{~A}$.U. from the oxygen nucleus, the two $\mathrm{OH}$ bonds making an angle of $104^{\circ} 3 \mathrm{I}^{\prime}$. Studies of the infra-red absorption and Raman frequencies characteristic of the $\mathrm{OH}$ bonds in water and ice ${ }^{8}$ show only slight alterations of these dimensions. The $\mathrm{OH}$ distance in ice may be 0.99 A.U. or even as much as $\mathrm{I} \cdot 05$ A.U., but it is certainly not as much as $\mathrm{I} \cdot 38 \mathrm{~A}$.U. If ice, however, is molecular and not ionic, then many atomic arrangements are possible, but all of them are more complex than the simple structure proposed by Barnes. The simplest molecular structure giving Barnes' observed X-ray data would be polar, with 12 molecules in the unit of pattern, while the simplest non-polar structure would have 96 molecules in its repeat unit. This all seems rather improbable, and Bernal and Fowler ${ }^{3}$ therefore made what was, in 1933 , the rather unusual suggestion that ice might be crystalline only in the positions of its molecules,. but glass-like in their orientation. This, presumably, implies a static irregularity of structure.

Pauling, ${ }^{9}$ however, has suggested a dynamic irregularity of structure, in order to explain the thermal ${ }^{10}$ and dielectric properties of ice. he says ${ }^{11}$ :

We ... assume that each water molecule is so oriented that its two hydrogen atoms are directed approximately towards two of the four surrounding oxygen atoms, that only one hydrogen atom lies along each oxygen-oxygen line, and that under ordinary conditions the interaction of non-adjacent molecules is such as not to stabilize appreciably any one of the many configurations satisfying these conditions with reference to the others. Thus we assume that an ice crystal can exist in any one of a large number of configurations, each corresponding to certain orientations of the water molecules. It can change from one configuration to another by rotation of some of the molecules or by motion of some of the hydrogen nuclei, each moving 0.78 A.U. from a position 0.99 A.U. from one oxygen atom to the similar position near the other bonded atom. It is probable that both processes occur. The fact that at temperatures above about $200^{\circ} \mathrm{K}$. the dielectric constant of ice is of the order of magnitude of that of water shows

* There is an overlap of these values in respect of possible errors of observation, but a strong probability that a real difference exists. 
that the molecules can reorient themselves with considerable freedom, the crystal changing in the stabilizing presence of the electric field from unpolarized to polarized configurations satisfying the above conditions. On cooling a crystal of ice to very low temperatures it is caught in some one of the many possible configurations; but it does not assume (in a reasonable period of time) a uniquely determined configuration with no randomness of molecular orientation.

Such statistical structures, both static and dynamic, are becoming increasingly familiar to the $\mathrm{X}$-ray crystallographer. They almost always have a mean structure which is comparatively simple. In the case of ice the mean structure is Barnes' simple one of a ditrigonal or dihexagonal bipyramidal unit cell containing four molecules only.

The exact mechanism by which the hydrogen atoms or nuclei can "jump" from one position to another is not yet understood. Such movements would have to be group phenomena, each oxygen being left at any given instant with only two protons attached. As Pauling points out, ice is so similar to water that the concentration of $(\mathrm{OH})^{-}$and $\left(\mathrm{H}_{3} \mathrm{O}\right)^{+}$ions present in ice must be very small. Ordinarily a jump of 0.78 A.U. across a potential barrier would be more than could be explained by ordinary thermal agitation of the $\mathrm{H}$ nuclei themselves, but Huggins ${ }^{12}$ has pointed out that thermal vibration of the oxygen atoms may be sufficient to reduce the mean separation of $2 \cdot 76 \mathrm{~A}$.U. to a much lower value (say 2.55 A.U., the value ordinarily found for hydrogen bonds), so that when separation again takes place, the $\mathrm{H}$ nucleus may well have changed partners.

Recent X-ray techniques 13 enable us to investigate not only the positions of the atoms, but also their thermal vibrations. If a sufficiently long exposure time is allowed, there appears, besides the ordinary Laue photograph, consisting of sharp, discrete spots, a diffuse pattern of spots and streaks whose intensity is markedly dependent upon temperature. The theory of these patterns has been worked out for cubic ${ }^{14}$ and for hexagonal ${ }^{15}$ structures; and for a number of simple substances, such as $\mathrm{NaCl}, \mathrm{KCl}$, metallic $\mathrm{Na}, \mathrm{Pb}, \mathrm{W}$, it has been shown that the diffuse pattern observed is just what would be expected, according to the theory, from the ordinary elastic vibrations of the atoms. That is not the case for ice. Simple elastic oscillations of the atoms in ice or any other hexagonal crystal would give a rather simple diffuse pattern, especially in an X-ray photograph taken with the incident beam along the hexagonal axis. It would consist of nearly elliptical diffuse spots, cross-sections of solids of revolution about the radius vector joining the spot to the origin (central beam trace) in each case. The actual diffuse patterns of ice are much more complex than this. Whether taken along the hexagonal axis ${ }^{16}$ or in a direction at right angles to this (see accompanying plate, Fig. I, p. I23), the diffuse spots are joined together in various directions by diffuse streaks, which may well have their origin in group movements of oxygen and hydrogen atoms or in group reorientation of molecules. The theoretical aspects of this question are now receiving consideration, but unfortunately the mathematics involved is difficult. The phenomena are certainly of thermal (dynamic) origin, for the diffuse pattern disappears at very low temperatures, although it is still visible at $-78^{\circ} \mathrm{C}$. (Barnes, loc cit.). It is interesting to find that the basal plane (oo.I) gives a very intense and persistent diffuse reflection, showing that there is considerable vibration of the atoms normal to that plane, another confirmation of the relative weakness of the atomic bonds along the [00.1] direction.* From the intensity of the whole diffuse pattern it is possible to make a very rough estimate of the root mean square amplitude of the atomic vibrations near to $0^{\circ} \mathrm{C}$. This is almost certainly greater than that in rock-salt ( $\sim 25$ A.U.) and probably more nearly as much as that in sodium ( $\sim .5$ A.U.). In spite of these large thermal vibrations, divergent-beam X-ray photographs 17 show that natural ice crystals are relatively perfect and not mosaic in texture, except on a macroscopic scale. On melting, the Laue and diffuse patterns of ice disappear abruptly and are replaced by the familiar water diffraction ring.

* According to crystallographic convention, a set of planes is indicated by round brackets, a direction (in this case normal to the planes) by square brackets. 


\section{UNUSUAL Forms OF ICE}

So far only the open, lace-like hexagonal structure of ice I has been considered. Other forms have been observed, notably six high-pressure forms. ${ }^{18}$ Some of these, if cooled to very low temperatures, change only slowly into ice I even at atmospheric pressure. By tak:ng advantage of this fact, McFarlan ${ }^{19}$ was able to take powder photographs of ice II (side-centred orthorhombic) and of ice III, and concluded that their structures were distorted and more compact forms of ice I. Less complete information, not all published, ${ }^{18}$ was found for ice V and ice VI. Generally speaking, the X-ray diagrams for high-pressure ice were too complex to analyse. The high density of ice VII ( $1 \cdot 6$ g./c.c. at 50,000 atmospheres and room temperatures) shows that that structure must be approaching a close-packed arrangement.

It has been suggested that forms other than ice I may also exist at ordinary pressures. Apparently cubic crystals have been obtained from various solvents, especially alcohol, at low temperatures, but these have never been shown to be pure water or to be truly cubic. Rau 20 observed isotropic crystals at about $-70^{\circ} \mathrm{C}$., but these only appear when organic vapours are also present ${ }^{21}$; though whether the crystals are of compounds of water plus impurity, or whether the presence of the vapour modifies the form of the pure ice crystals is not certain. The most convincing work is that of König, ${ }^{22}$ who condensed water-vapour on to a collodion film at about $-80^{\circ} \mathrm{C}$. in a vacuum and showed, by electron diffraction patterns, that the crystals so formed had a diamond-like structure (see Fig. I, p. 123), with the distances between oxygen atoms 2.75 A.U. exactly as in ice I at the same temperature. König suggested that his diamond-like ice might be Bridgman's metastable ice VI, or its low-pressure equivalent, but the high symmetry makes this unlikely. In spite of König's precautions, the possibility that impurities were present in his apparatus is not excluded. It is difficult to imagine, however, that a structure of which any likely impurity formed an integral part would give so simple and easily interpreted a pattern as that published by König, or that the structure would be so closely related to ice I. Both Rau and König state that their crystals changed to the hexagonal form (ice I) on warming above about $-70^{\circ} \mathrm{C}$, and König supports this by microphotometer records.

Non-crystalline, or vitreous ice, could only be obtained at temperatures below about $-120^{\circ}$ C..$^{23}$ and it reverted to ice I on warming above $-70^{\circ} \mathrm{C}$.

Another recent report of a non-hexagonal form of ice is that of Seljakor, ${ }^{24}$ who has suggested that ice formed between $0^{\circ}$ and $-5^{\circ} \mathrm{C}$. is usually hexagonal, but that ice formed below $-5^{\circ} \mathrm{C}$. is more often rhombohedral (pseudo-cubic). His conclusions are based on Laue photographs (of which only sketches are given), powder photographs and a single rotation photograph. But they do not, in fact, bear close examination, for he has omitted to perform simple and quite crucial experiments, and all the results that he does obtain can be readily explained either by mis-setting or by preferred orientation. For example, he states that in the case of hexagonal $(\alpha)$ ice, the unique axis is within $0.5^{\circ}$ to $5^{\circ}$ of the normal to the surface of the sheet ice he used, but that in the case of rhombohedral $(\beta)$ ice, the unique axis is from $5^{\circ}$ to $10^{\circ}$ from that normal. Now one of the present authors (P. G. O.) has found that it is possible to get an apparently pseudo-trigonal Laue picture from ordinary hexagonal ice when it is mis-set by a few degrees from the hexagonal axis; and in the absence of proof to the contrary it seems likely that Seljakov's $\beta$-crystals were, in fact, mis-set $\alpha$-crystals. On grinding the so-called $\alpha$ and $\beta$ crystals at $-8^{\circ} \mathrm{C}$. and then pressing the powders into capillary tubes he obtained identical X-ray powder photographs from the two forms, in each of which the 00.2 reflection was missing. The rapid freezing of water in a capillary tube at $-S^{\circ} \mathrm{C}$. gave him a powder photograph consisting of the same lines, though with somewhat different intensities, plus a very strong 00.2 reflection. He assumes that the absence of 00.2 is typical of the hexagonal form (into which the $\beta$-crystal must, he says, have been converted by grinding!), the presence of 00.2 typical of the rhombohedral form. It is far more likely that in pressing his powders into capillary tubes in his first experiment he oriented them (as one always does unless special 
precautions are taken) so that the (Oo.r) planes could not reflect. He could have tested this by turning his capillary tubes through $90^{\circ}$ with reference to the incident beam and then oscillating through a wide angle. Finally he took a rotation photograph of one of his single $\beta$-crystals and showed that it gave a 00.2 reflection but did not, apparently, take a rotation photograph of an $\alpha$-crystal (although he says he was able to keep these single crystals for many hours) to prove that that did not! We are quite convinced that had he done so, he would have found that both $\alpha$ and $\beta$ crystals (if properly set) gave identical rotation photographs, and that these would have been the same as those published by Barnes and confirmed by ourselves.

The conclusion is that only one form of natural ice has been proved to exist at ordinary pressures and that the structure of this is as shown in Fig. 2, but with some uncertainty as to the positions and movements of the hydrogen atoms. It is possible that the structure shown in Fig. 3 may be obtained at temperatures below $-70^{\circ} \mathrm{C}$. and under special conditions. There are also a number of high-pressure forms of ice, the structures of which have not been ascertained with any certainty.

\section{ACKNOWLEDGEMENTS}

The original work referred to in this paper was carried out at the Davy Faraday Laboratory of the Royal Institution, by the aid of a grant from the Agricultural Research Council.

\section{R E F E R E N C E S}

I. Lonsdale, K. and Owston, P. G. Nature, Vol. 157, 1946, p. 479.

2. Adams, J. M. Proc. Roy. Soc. A, Vol. 128, 1930, p. 588.

3. Hettich, A. and Schleede, A. Z. Physik, Vol. 50, 1928, p. 249 ; Wooster, W. A. quoted by Bernal, J. D. and Fowler, R. H. Fourn. Chem. Physics, Vol. I, I933, p. 515.

4. Barnes, W. H. Proc. Roy. Soc. A, Vol. 125, 1929, p. 670; Bragg, W. H. Proc. Phys. Soc., Vol. 34, 1921, p. 98 ; Dennison, D. M. Phys. Review, Vol. 17, 1921, p. 20.

5. Megaw, H. D. Nature, Vol. 134, 1934, p. 900.

6. McConnel, J. C. Proc. Roy. Soc. A, Vol. 59, r891, p. 323.

7. Darling, B. T. and Dennison, D. M. Phys. Review, Vol. 57, 1940, p. 128.

8. Fox, J. J. and Martin, A. E. Proc. Roy. Soc. A, Vol. 174, 1940, p. 234 ; Trans. Faraday Soc., Vol. 36 , I 940 , p. 897 .

9. Pauling, L. Fourn. Amer. Chem. Soc., Vooi. 57, 1935, p. 2680.

10. Giauque, W. F. and Ashley, M. Phys. Review, Vol. 43, 1933, p. 81 Giauque, W. F. and Stout, J. W. Journ. Amer. Chem. Soc., Vol. 58, 1936, p. 1144.

I1. Pauling, L. Nature of the Chemical Bond, and edition, Cornell University Press, 1945, p. 302.

12. Huggins, M. L. Fourn. Phys. Chem., Vol. 40, 1936, p. 723.

13. Lonsdale, K. Proc. Phys. Soc., Vol. 54, 1942, p. 314 ; Reports on Progress in Physics, Phys. Soc., Vol. 9, 1942-3, p. 256.

14. Jahn, H. A. Proc. Roy. Soc. A, Vol. 179, 1942, p. 320 ; Vol. 180, 1942, p. 476.

15. Begbie, G. H. and Born, M. Proc. Roy. Soc. A, Vol. 188, 1947, p. 179; Begbie, G. H. ibid., p. I89.

16. Lonsdale, K. Nature, Vol. 1 58, 1946, p. $5^{82}$.

17. Lonsdale, K. Phil. Trans. Roy. Soc. A, Vol. 240, 1947, p. 219.

18. Bridgman, P. W. Fourn. Chem. Phys., Vol. 3, 1935, p. 597 ; Vol. 5, 1937, p. 964; Rev. Mod. Phys., Vol. 18, I 946 , p. I.

19. McFarlan, R. L. Fourn. Chem. Phys., Vol. 4, 1936, pp. 60, 253.

20. Rau, W. Schrift. Deut. Akad. Luft, Vol. 8, r944, p. 65.

21. Cwilong, B. M. Fourn. Glaciology, Vol. 1, 1947, p. 53.

22. König, H. Z. Krist., Vol. 105, 1944, p. 279 ; $c f$. Nature, Vol. 1 57, 1946, p. 449.

23. Burton, E. F. and Oliver, W. F. Proc. Roy. Soc. A, Vol. 153, 1935, p. 166; König, H. loc. cit.

24. Seljakov, N. C.R. Acad. Sci. U.R.S.S., Vol. 10, 1936, p. 293 ; Vol. 11, 1936, p. 227; Vol. 14, 1937, p. 181 . 
Fig. I. Laue photograph of ice, using unfiltered radiation from a copper target; incident beam $1 \mathrm{~mm}$. diameter, exposure time one hour; temperature about $-5^{\circ} \mathrm{C}$. Crystal orientation: [oo.I] axis vertical, incident beam nearly parallel to (II.O) plane. Cylindrical film. Showing sharp Laue spots and diffuse thermal vrbration pattern superimposed. Note the strong 00.2 thermal reflection a little way above the central spot, although the (00.2) plane is horizontal

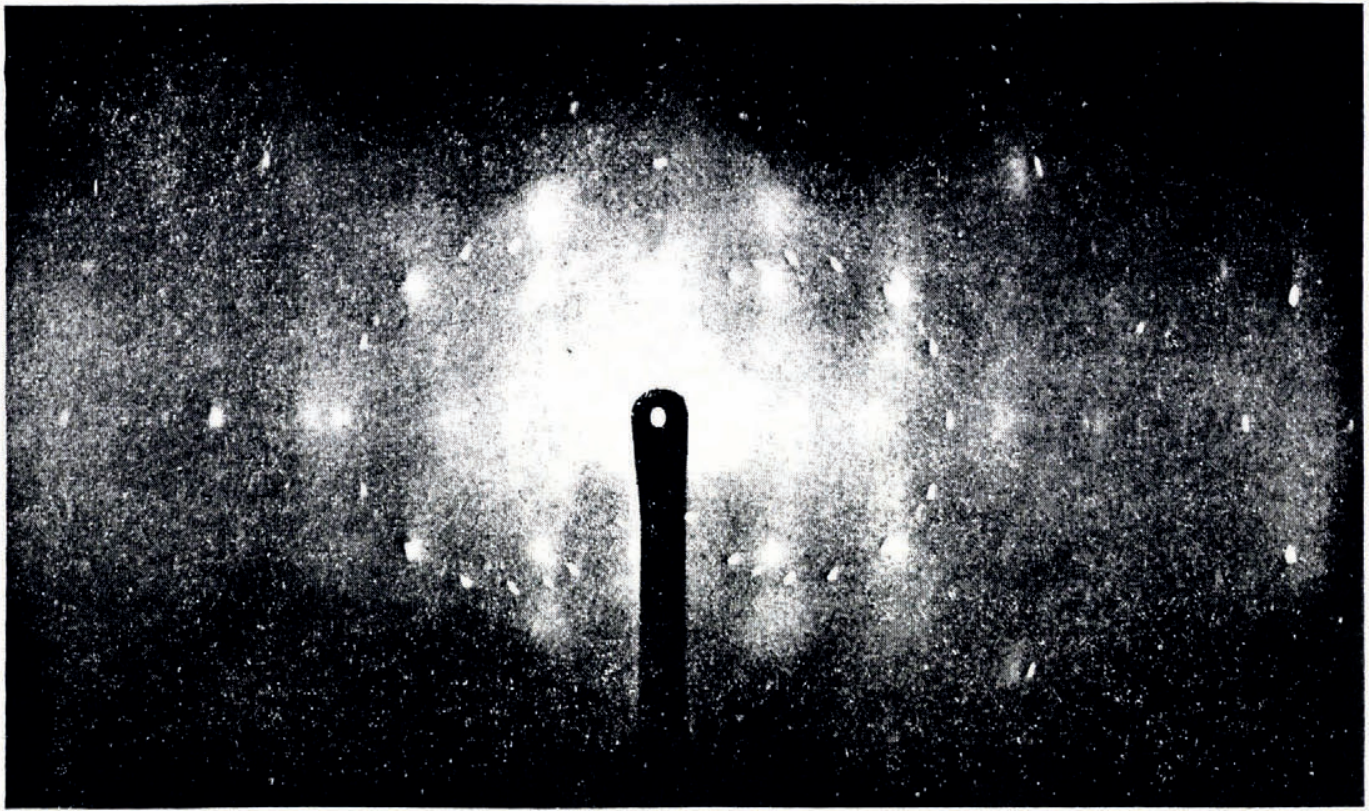

(a)

(b)

(a)
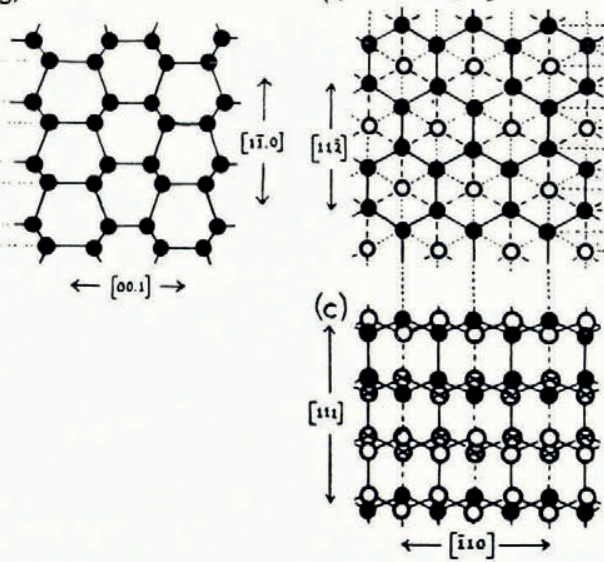

Fig. 2. Hexagonal Ice

(a) Projection along [oo.I]

(b) Projection along $[11.0]$

(c) Projection along $[\bar{x} \bar{x} .0]$

Fig. 3. Cubic Ice (König)

(a) Projection along [III]

(b) Projection along $[\overline{\mathrm{I}} \mathrm{I} \mathrm{O}]$

(c) Projection along $\left[\begin{array}{ll}I & \overline{2}\end{array}\right]$ 